Is it not true that many operations successful today would have remained in their undeveloped infancy had not the faith of certain internists been greater than the surgical results justified at the time? Those of us who are struggling with the surgery of chronic lung infections wish only to convince physicians that we are conservative; that we are not inclined to attack unsuitable cases; that we are working along lines of surgical propriety; that already we can relieve; and that eventually, with added experiences, we may cure some of these cases which seem to defy medication.

72 East Seventy-Ninth Street.

\section{THE APPLICATION OF THE VAN SLYKE AMINONITROGEN DETERMINATION TO THE DIAGNOSIS OF CANCER *}

OTTO LOWY, M.D.

Clinical Assistant, Post-Graduate Hospital and Medical School, New York; Serologist, Beth Israel Hospital NEWARK, N. Y.

In working with the Abderhalden reaction in pregnancy or cancer we are dealing with a reaction which lends itself admirably to diagnostic work. With this reaction, as with all other laboratory tests, we are dealing with something which does not and cannot give absolutely accurate results (clinically). But experience has shown that the results obtained are accurate in a sufficiently large percentage of the cases to give it a place in the diagnostic armamentarium of the clinician.

It is not my intention in this short paper to give a description of the technic of the thimble method, nor to go into details of the theory on which this test is based. The thimble method, which is the method advocated by Abderhalden, and which is being used all over the world, contains a number of errors which appear at the most unexpected times and which invalidate the test to such a degree that the test either cannot be read, and must be repeated, or else the reading assumes the guise of guessing. I will briefly enumerate some of these errors.

1. The most constant error is in the serum of the patient. The blood of the patient at all times contains amino-acids. Shortly after meals, during the height of digestion, the amino-acid content of the blood may be decidedly increased. ${ }^{1}$ Or, again, in certain cases of malnutrition there is an abnormal increase of ninhydrin-reacting substances which diffuse readily through animal membrane. It will be seen, then, if serum from a patient containing a high amino-acid content be used, the dialysate of the test serum, as well as the controls, will give a color reaction with ninhydrin.

2. If in taking the blood from the patient, the blood is permitted to drip into a container, or if during centrifugalization some of the red blood cells should be broken up so as to free the hemoglobin, the same error will occur as above.

3. No matter how careful we may be in having all of our glassware absolutely clean and sterile, accidental contamination may occur.

4. Owing to the fact that it is impossible absolutely to sterilize the thimbles without boiling, another error may sometimes occur.

* From the Laboratory of Pathological Chemistry and the Department of Medicine, New York Post-Graduate Medical School and ment of

1. Van Slyke and Meyer: Jour. Biol. Chem., 1912, xii, 399.
5. The thimbles, through careless handling, may become bruised or weakened at some point so as to allow protein to penetrate into the dialysate or else, if we boil our thimbles, the meshes become tightened so that they do not permit even peptones to pass.

6 . In boiling the dialysate with the ninhydrin over the gas flame for one minute, as advocated by Abderhalden, a different degree of intensity of heat must undoubtedly be obtained by the most careful worker. I have tried, and I believe successfully, to overcome this error by boiling all the test tubes in a water bath at the same time for ten minutes.

From the foregoing it will readily be seen how extremely difficult and how extremely painstaking we must be in order to obtain accurate results. At the suggestion of Prof. V. C. Myers of the Post-Graduate Hospital Medical School, I have been using the Van Slyke aminonitrogen apparatus, which Dr. Van Slyke of the Rockefeller Institute of New York devised for the purpose of measuring the aminonitrogen content of the blood.

The rationale of this method is that we are able to determine accurately the amount of aminonitrogen liberated or given off in a given quantity of serum. ${ }^{2}$ We add dried cancer substrate (prepared in the same manner as for the thimble method and then dried) to the suspected serum in a test tube and take another test tube which contains suspected serum alone, cover the serum with a layer of toluene and incubate for twenty-four hours. If the suspected serum is the serum of a cancer patient and contains a sufficient quantity of the proteolytic enzyme, a reaction will take place. After measuring the amount of aminonitrogen liberated from the serum alone, and then measuring the amount of aminonitrogen liberated from the serum plus substrate, we find that the amount of the latter is increased over the former by anywhere from 0.05 to 0.15 c.c.

In three cases of cancer with cachexia I observed that the amount of nitrogen liberated in the serum plus substrate was decreased anywhere from 0.4 to 0.1 under the amount of nitrogen liberated from the serum. Inasmuch as I did not at that time use the dried cancer substrate, Dr. Van Slyke suggested that the amount of fluid in the moist substrate may have diluted the serum to a great extent so as to account for that decrease. In preparing the substrate for this test we must be careful to rid the substrate of all soluble proteins, and before using the same it must be tested to determine whether any nitrogen is given off by the substrate. Should this be the case, the substrate must be discarded. The total number of cases examined by the Van Slyke method was eighty-two. Of these forty-two were clinically and pathologically diagnosed as cases of carcinoma, which were divided as shown in the accompanying tabulation:

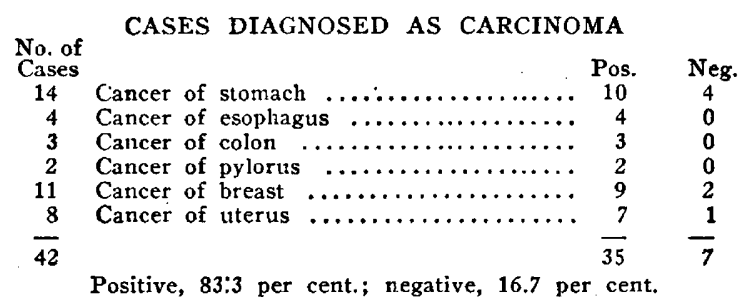

2. Van Slyke and Vinograd: Proc. Soc. Exper. Biol. and Med., May $20,1914$. 


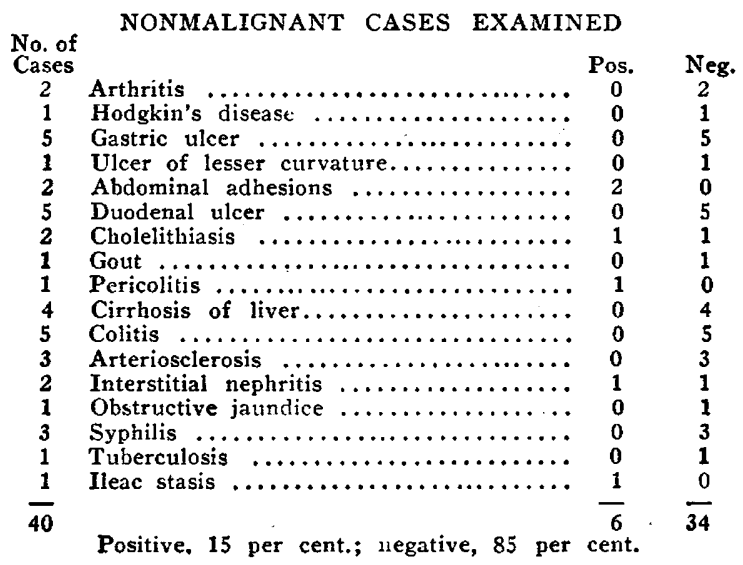

In all the cases tabulated the substrate used was obtained from carcinoma of the breast. All the cases, with a few exceptions, were tested in the laboratory of pathologic chemistry of the Post-Graduate Hospital, New York.

\section{CONCLUSIONS}

While the number of cases examined is small, nevertheless, I believe that if Abderhalden's theory should prove to be the correct one, the Van Slyke aminonitrogen apparatus will give us more satisfactory results than the thimble method, for the following reasons:

1. The Van Slyke method is very accurate if performed properly.

2. The blood of the patient may be taken at any time, even shortly after meals. The addition of hemoglobin does not invalidate the test.

The percentage obtained in my series of cases should not be considered absolute, for we are unable to figure an absolute percentage on such a small number of cases. It would be preferable to have examined at least 500 cases before any definite percentage of results was announced.

190 Clinton Avenue.

\section{THE NECROPSY AS A PUBLIC SERVICE}

\section{LOUIS B. WILSON, M.D.} ROCHESTER, MINN.

The very careful investigation of the subject of post-mortem examinations in the United States made two years ago by a committee of the New York Academy of Medicine ${ }^{1}$ showed that of the seventeen large hospitals in the United States from which statistics were available for the years 1910, 1911 and 1912 , the ratio of necropsies to deaths ranged from 7.3 to 62.7 per cent. In only four was the percentage above 25 . As a reason for these very low percentages as compared with those of European hospitals, the committee states that "the main causes of the difficulties in obtaining permission for necropsies are due (a) to the ignorance on the part of the public of the importance of necropsies to science and therefore to the welfare of the people; $(b)$ to the existing inadequate laws; $(c)$ to the activity of undertakers and cer-

1. Report of Public Health, Hospital and Budget Committee, New York Acad. of Med., Tine Journal A. M. A., June 7, 1913, p. 1784. tain funeral societies; $(d)$ to the inadequate rules of hospitals in this respect; and $(e)$ to the claims of the department of anatomy."

While the foregoing are no doubt important deterring factors, I believe that much more important are (a) the lack of genuine interest in post-mortem examinations on the part of many physicians and surgeons, and $(b)$ the lack of a commendably selfish interest in post mortems on the part of intelligent relatives of the dead.

Some physicians entirely lack an interest in necropsies because they are not interested in accurate vital statistics and in problems of heredity in disease, or because they do not appreciate the value of the necropsy in the correction of errors in diagnosis. Possibly some also hesitate to bring their diagnoses or operative procedures to the test of publicity in the necropsy.

Most intelligent laymen will respond to the argument that they ought to know the weaknesses of the members of their own families, but this argument is frequently omitted or greatly subordinated by the physician proposing that a necropsy be made. Usually necropsies are asked for as a favor to the physician, and rarely offered as a favor to the relatives.

The policy of the desirability of checking diagnoses and the results of operative procedures by the necropsy findings and of presenting to the relatives the desirability of their knowing the exact cause of death and the presence of intercurrent diseases has been followed out in the Mayo Clinic for many years. As a result, during the triennial period, 1910-1912, in 626 deaths, 512 necropsies were made, or 81.8 per cent.; in 1913 there were 269 deaths and 227 necropsies, or 84.4 per cent.; in 1914, 293 deaths and 258 necropsies, or 88 pe: cent., while to date (March 17) in 1915, there have been 73 deaths with 73 necropsieș, or 100 per cent.

Of the hospitals surveyed by the committee of the New York Academy of Medicine, which have patients of about the same social conditions as those in the Mayo Clinic, the two in America showing the highest percentage of necropsies to deaths are the Johns Hopkins Hospital of Baltimore and the Royal Victoria Hospital of Montreal. During 1910, 1911 and 1912, the former had 346 post mortems, or 62.7 per cent. of its deaths, and the latter had 560 post mortems or 67.6 per cent. of its deaths.

\section{NEED FOR NECROPSIES}

At present our most accurate vital statistics concerning the cause of death from functional and chronic diseases are derived from the records of patients in charity hospitals. The charity patient, who for years has been examined and treated by physicians working in a public capacity before students, or at least using their knowledge for the teaching of students, as a rule receives thorough scientific diagnosis and treatment; and, supplementing this, the charity patient on whose body, in case of death, a necropsy is performed, is the subject of a death certificate which closely approximates the facts. But we must recognize that inferences drawn from statistics compiled from the records of great charity hospitals are apt to be more or less misleading when applied to specific cases in the estimation of family inheritance or life expectancy in the well to do. If Mendel's laws are of any value, forecasts of probable heredity can 